\title{
Improvements in small scale artisanal cheesemaking via a novel mechanized apparatus
}

\author{
Patrícia J.M. Reis, F. Xavier Malcata* \\ Universidade Católica Portuguesa, Escola Superior de Biotecnologia, Rua Dr. António Bernardino de Almeida, P-4200-072 Porto, Portugal \\ * Corresponding author. Tel.: +3512255800 04; fax: +351 2250903 \\ 51. E-mail address: fxmalcata@esb.ucp.pt (F.X. Malcata).
}

\begin{abstract}
The current research effort consisted on design, building and testing of a customized apparatus - a closed cylindrical, double-jacketed cheese vat, with a 50 L-capacity, aimed at manufacturing Serra da Estrela cheese (or similar ewe's milk cheeses), provided with knives that play a double role - stirring and cutting, a combined device for draining and pre-moulding, and a cleaning-in-place system. This novel apparatus makes it possible to semi-automate cheesemaking in small scale - including a continuous cycle of hands-free sequential coagulation, cutting, syneresis and moulding of cheeses. It was successfully applied to ewe's milk cheese manufacture, and was able to reduce duration of the overall cycle - with concomitant standardization of the process, and a significant $(P<0.05)$ increase in cheese yield and fat recovery.
\end{abstract}

Keywords: Dairyfoods;Technology;Traditionalcheese;Ewe'smilk; Yield;Innovation

\section{Introduction}

Mediterranean countries - and Portugal in particular, are characterized by existence of several artisanal cheeses, manufactured from ewe's and goat's raw milks. These products have been increasing in popularity among consumers, because they are unique in texture and flavour which make them rather different from cheeses obtained from cow's milk (Freitas, Macedo, \& Malcata, 2000). Portuguese artisanal cheeses represent $22 \%$ of all cheese sales in that country - of which only $6 \%$ are Appelation d'Origine Protégée (AOP) cheeses, of 11 different types. The most famous are Serra da Estrela, Serpa, Azeitão and Castelo Branco - which were granted their AOP status between 1985 and 1988. Those raw ewe's milk cheeses exhibit a soft paste - which makes them easy to spread (as a result of extensive proteolysis), and a notable lipolyzed character. Serra da Estrela is still the most important Portuguese vari- ety of traditional cheese, in organoleptic and economic terms: widely recognized as a nuclear part of the gastronomic and social heritage, it accounts for c. 100 ton annually (IDRHa-MADRP, 2005); and it is produced in small dairy farms located in the highest mountains in Portugal, via coagulation brought about by flowers of the wild plant Cynara cardunculus. That cheese can be described as a semi-soft cheese with a flat cylindrical shape, a strong aroma and a slightly acid taste. The moisture content ranges from $61 \%$ to $69 \%$ (on a fat-free basis), whereas the fat content ranges from $45 \%$ to $60 \%$ (on a dry matter basis) - as described in the Portuguese legal standard (NP-1922, 1985).

Official figures provided by ANCOSE (National Association of Breeders of Bordaleira Serra da Estrela Ewes, Oliveira do Hospital, Portugal) indicate that there are ca. 3700 producers of ewe's milk in Serra da Estrela region, who commercialize a total of ca. 9,600,000 L of milk per year - which is almost all used to manufacture 1920 ton of cheese. However, owing to the legal and technical requirements established by its AOP status, only ca. $5 \%$ of that cheese can actually be certified as Serra da Estrela cheese. 
Farmers in such a geographical region are thus allowed to produce non-AOP ewe's cheese, but only certified cheeses can reach a premium price in the market: typical prices are 13 and $16 € \mathrm{~kg}^{-1}$, for regular and certified cheese, respectively.

Despite the large variety of ewe's cheeses in Portugal, only very few types are manufactured on the industrial scale - likely because of the lack of feedstock milk, coupled with the poor knowledge of the relationships between technological protocols, on the one hand, and biochemical and microbiological characteristics of the final cheeses, on the other. Furthermore, deeply entranched historical and cultural constraints have not permitted scaleup of artisanal cheese manufacture - because each farmer fears mixing his milk feedstock with those obtained from herds of other farmers, characterized by different sanitary states; this means that pooling of milks and large-scale, cost-effective mechanization of cheesemaking are not feasible at all.

A few research studies have meanwhile been published, that focus on artisanal cheeses manufactured from ewe's and goat's milks - encompassing especially quantification of and identification within microbial groups; one good example is the work by Tavaria and Malcata (1998), who studied the quantitative and qualitative microbiological evolution in Serra da Estrela cheese throughout ripening. Technological studies were also performed pertaining to that cheese, and encompassed such easily manipulated parameters as temperature and time of coagulation, pressing, and temperature and humidity during ripening, and their effects on final cheese yield and organoleptic characteristics (Macedo \& Malcata, 1997; Macedo, Malcata, \& Oliveira, 1997; Macedo, Tavares, \& Malcata, 2004). In attempts to optimize cheesemaking, a few experimental cheeses were actually manufactured, using temperature of coagulation, and amount of rennet and amount of salt added as technological variables (Macedo \& Malcata, 1997; Sousa \& Malcata, 1997a, 1997b). Vasconcelos (1990), on the other hand, attempted to assess the effect of the manufacture protocol on Azeitão cheese final quality; procedures tested included use of double-walled cheese vats, and of horizontal and vertical knives, defined additions of rennet and $\mathrm{NaCl}$, and control of temperature and time for each step. Technological studies pertaining to Castelo Branco cheese were conversely rather basic; Dias (1992) unfolded a need of technological standardization, so as to improve the microbiological quality of that cheese. Roseiro, Wilbey, and Barbosa (2003) examined how Serpa cheese, produced either by artisanal or semi-industrial procedures, relates to the regulatory specifications of this type of cheese - and compared the two procedures, in biochemical and microbiological terms; despite the highly significant differences found between artisanal and semiindustrial cheeses, both products lied within the official limits for specifications set forth by national regulations.

Recall that the major operations included in manufacture of cheeses are milk handling, coagulation, cutting, syneresis, pressing, salting and ripening; however, each of them is applied in distinct ways depending on the cheesemaker, thus giving rise to rather different final products. In addition, the manufacture protocol is typically labourintensive: operations are carried out manually, which, besides the higher and higher cost of human workforce, introduce undesirable contamination by the cheesemaker's hands, as well as by utensils employed thereby - due to unavoidable human variations and unpredictable environmental inputs, which also raise the risk of cheesemaker's injuries at the various stages that employ metallic tools.

Therefore, the major purpose of this research work was to design a customized cheesemaking apparatus specifically for the small dairy farmer - with an operating volume of the order of $50 \mathrm{~L}$, with controlled temperature and whey withdrawal, which is compact in size, and simple and robust to operate, and which carries about affordable cost advantages. Ideally, said apparatus should provide better control over moisture, protein and fat contents of the curd, as well as avoid hand contact - so as to produce a more uniform end product.

\section{Materials and methods}

\section{Artisanal manufacture}

In the preparation of Serra da Estrela cheese (or the like), ewe's raw milk is filtered through a fine, clean cloth into a water-jacketed cheese vat; when the desired temperature $\left(28-32{ }^{\circ} \mathrm{C}\right)$ is reached, dry thistle flower (usually C. cardunculus $\mathrm{L}$.), at a rate of $0.2 \mathrm{~g} / \mathrm{L}$ of milk, is placed inside a cloth with closed ends, submerged in milk, hand-macerated and thoroughly stirred. The mixture is then left at $32{ }^{\circ} \mathrm{C}$, until coagulation has taken place (typically ca. $45 \mathrm{~min}$ ). Afterwards, the curd is manually worked via stirring with the bare hand (or pseudo-knives), and allowed to set for ca. $10 \mathrm{~min}$ (so as to initiate syneresis). The curd is then pressed - the small and irregularly shaped pieces of curd (together with accompanying whey) are thus poured into a fine, widethreaded cloth bag, squeezed between the fingers, and then slowly (but firmly) pressed by hand for c. $10 \mathrm{~min}$ so as to aid in expression of whey. Drainage of whey is completed via pressing, at ca. $25 \mathrm{~N} \mathrm{~cm}^{-2}$ and for ca. $4 \mathrm{~h}$, the fresh cheese while in the moulds, via a standard pneumatic press. During such a period of time, the moulds are reversed a number of times, so as to aid in making the resulting cheese become as homogeneous as possible. Each fresh cheese (ca. $1 \mathrm{~kg}$ in weight, ca. $11 \mathrm{~cm}$ in diameter and ca. $6.5 \mathrm{~cm}$ in height) is finally stored in a first chamber kept at $8{ }^{\circ} \mathrm{C}$ and a relative humidity of $99 \%$ for three wk (during which it is turned upside down daily), and then transferred to a ripening chamber at $11{ }^{\circ} \mathrm{C}$ and a relative humidity of $85 \%$.

\section{Equipment description}

General features

The novel cheesemaking apparatus is shown in Fig. 1. It is made from stainless steel AISI 304; as the dairy feed- 
stocks are not particularly aggressive to the container metal and the cleaning chemicals are only moderately corrosive, AISI 316 was not required in this case. Such apparatus comprises a closed cylindrical, double-walled vat - which is $515 \mathrm{~mm}$ long and $484 \mathrm{~mm}$ in diameter, and which is maintained at $120 \mathrm{~cm}$ from the ground by a series of two legs. The two concentric walls form a jacket of ca. $15 \mathrm{~mm}$ in thickness, through which heating water may be circulated (at a flow rate of ca. $10 \mathrm{~L} \mathrm{~min}^{-1}$ ) from an external, gas-operated heater. Hot water is supplied to the jacket through an inlet tube, connected to the lower part of the vat. The upper end of the cheese vat is closed by a lid, with an opening used to add the (plant) rennet (Fig. 2b). The rotating stirring/cutting frame is located within the vat, and attached to the cover; it is vertically positioned along only one side of the vat to stir the milk, as well as to stir and cut the curd formed after having added the (plant) rennet. The cover of the vat is mechanically lifted by switching on the corresponding engine in the control panel - hence allowing access of the operator to the interior of the vat for check up, or replacement of the stirring/cutting frame. For security and functionality, this apparatus is equipped with three proximity detectors: one controls the maximum and minimum aperture of the cover, another interrupts the movement of the stirring/cutting frame, and a third determines the position at which the stirring/cutting frame is to rest when motion is stopped.

\section{Stirring and cutting}

The cutting frame is provided with a set of 11 vertical cutting knives, which are spaced $15 \mathrm{~mm}$ from each other. The cutting knives are arranged in attack angle for longitu-
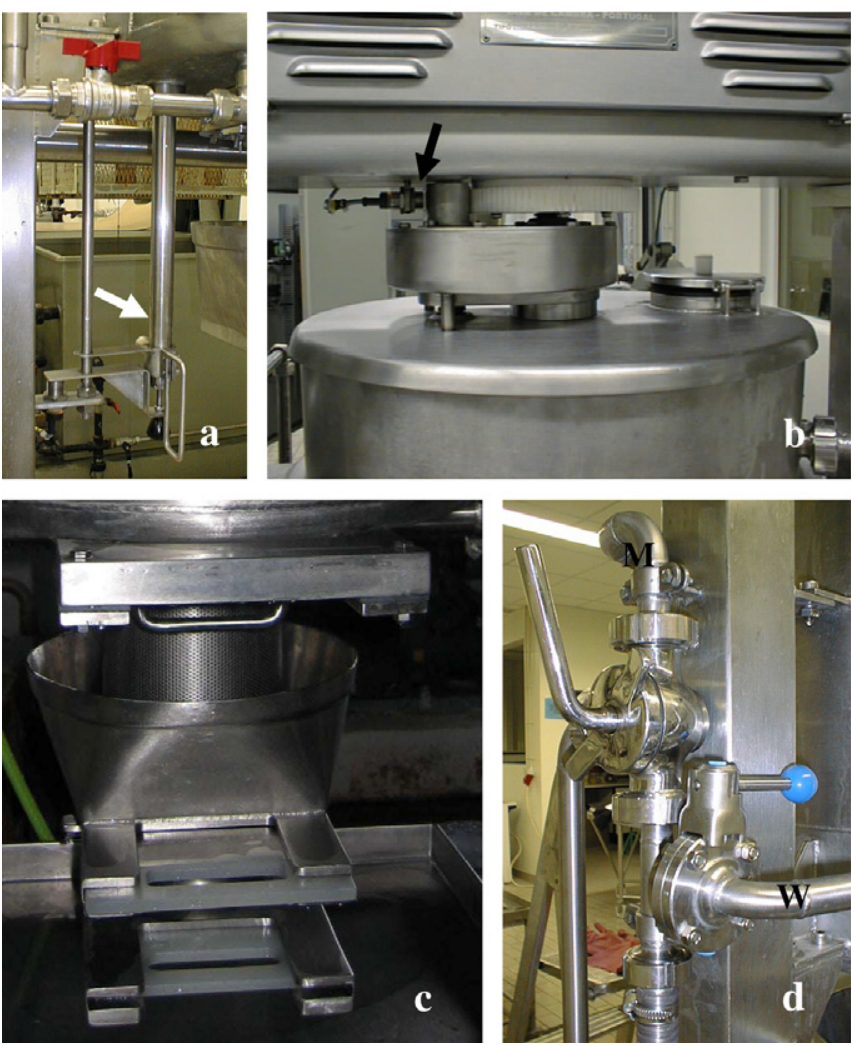

Fig. 2. Building details of the novel cheesemaking apparatus: (a) periscope for drainage (white arrow); (b) upper end of cheese vat, showing the lid with opening used to add the (plant) rennet, and the detector that determines the position at which the stirring/cutting frame is to rest when the motion is stopped (black arrow); (c) perforated cylinder, inside which pre-moulding of cheese takes place; and (d) inlet tubes, through which milk (M) and water for cleaning (W) are admitted into/out of the cheese vat.
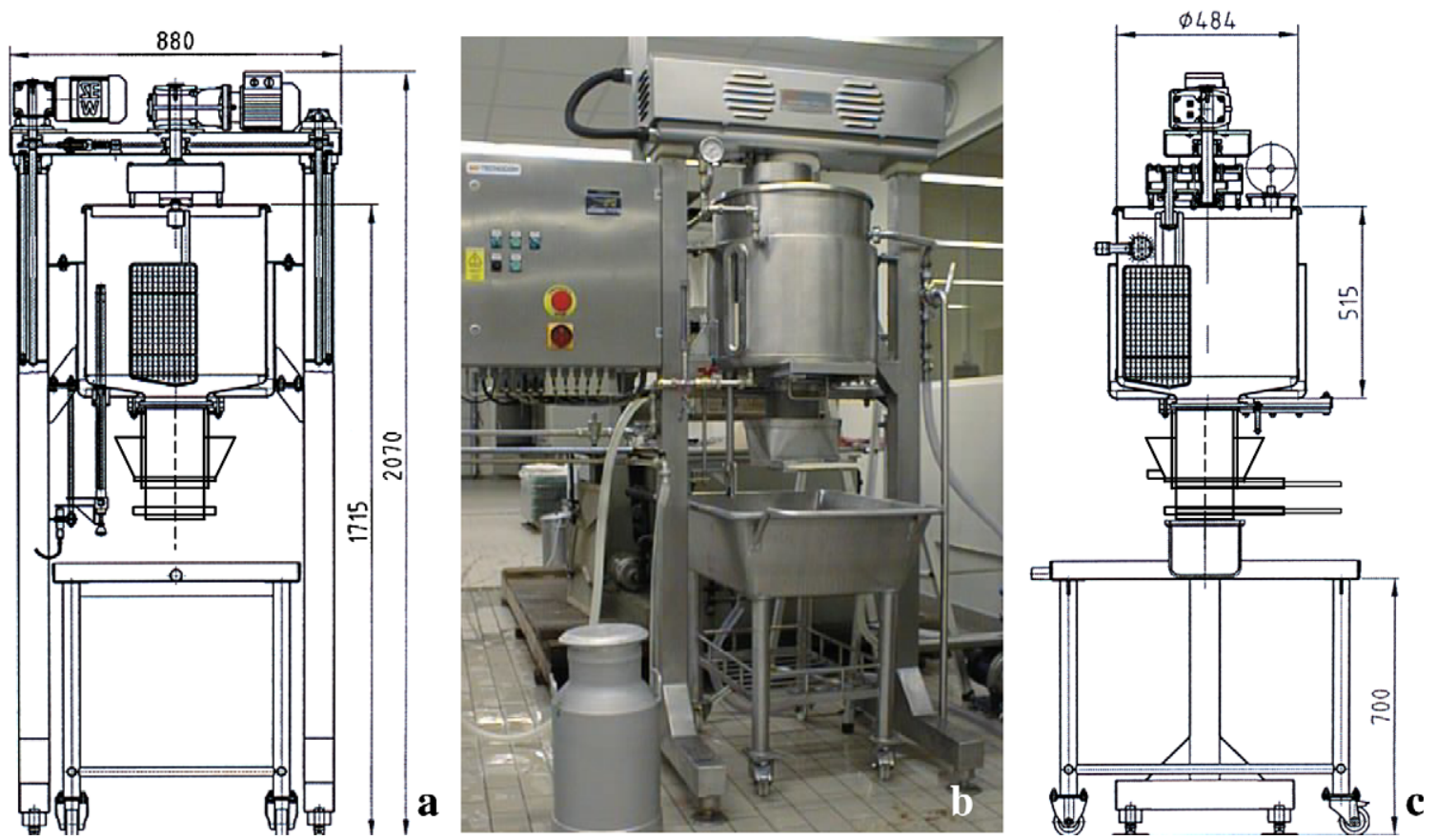

Fig. 1. Front view - (a) diagram and (b) photo, and side view - (c) diagram, of the novel cheesemaking apparatus. 
dinal cutting of the curd in its direct rotation, and for stirring the milk or curd in its reverse rotation; the engine that provides the rotational movement is controlled by the operator, via a variable speed switch in the control panel. The knives remain in place during the entire cheesemaking process, but they may be lifted for tentative adjustment or preventive maintenance.

The vat is equipped with a thermostat/sensor - which allows setting the temperature of the milk and curd within the vat by the manufacturer, again via a knob in the control panel. Continuous in situ observation of milk and whey is possible via a narrow glass window, provided with a vertical scale to assess filling capacity. The bottom edges of the vat are slightly $\mathrm{V}$-shaped, so as to provide a slope toward the axis of the vat that is adequate for drainage. The milk is supplied from the outer refrigerated tank, through an inlet located in the upper edge of the vat, via a centrifugal pump operated at variable speed (and thus variable flow rate).

\section{Whey draining and moulding}

The cheesemaking vat is provided with a vertical, telescopically extensible tube, mounted on the bottom edge of the vat - a periscope, which is designed for selective drainage of whey (Fig. 2a). When said periscope is manually pulled up into the vat, the stirring/cutting frame stops automatically due to the aforementioned proximity detector. The upper aperture of the periscope allows whey to vent to the exterior of the vat, down to a level that depends on the inner depth of said periscope.

The lower end of the vat has a mobile blocking plate, which manually opens into a vertical circular tube with perforated walls - that allow whey to escape from the curd, and the dimensions of which are set as those desired for the final cheese (Fig. 2c). A perforated cylinder - inside which pre-moulding of curd takes place, can be attached to the lower end of the vat by brackets; on the other end, it possesses a blocking plate. A mobile cutting frame is positioned at a selected point in the cylinder, so as to allow manufacture of uniformly sized cheeses (one at a time).

An independent table - resting on four legs (two of which with wheels) and bearing a $1 \%$-slope, can be placed below the vat; it serves to collect the whey discharged, and place the moulds already filled with curd.

\section{Cleaning and sanitation}

The cheese vat is provided with a cleaning-in-place (CIP) system, which allows automatic cleaning of the inside of the apparatus. A washing tank can then be linked to the cheesemaking vat. A water spray nozzle (header) is provided in the upper edge of the vat; hot water under pressure is pumped through it, as supplied from the tank via a centrifugal pump (Fig. 2d). While in this stage, the inner wall and the cutting/stirring frame are sprayed with hot water - to remove any residual cheese curd that may have been left.

\section{Experimental manufacture}

\section{General performance}

Three comparative cheesemaking trials were conducted in three consecutive days. In each trial, Serra da Estrela cheese was manufactured from a given raw milk batch using the novel cheesemaking apparatus, whereas a control cheese was manufactured from the same batch following the classical mode - as described in detail by Macedo, Malcata, and Oliveira (1993).

In the case of the experiments using the novel apparatus, $40 \mathrm{~L}$ of raw ewe's milk was pumped from the refrigerated tank, through the delivery piping, to the vat previously warmed to $35^{\circ} \mathrm{C}$ (by circulating hot water), and gently stirred via the cutting frame (see Fig. 3). Macerated thistle flower ( $C$. cardunculus $\mathrm{L}$., at a rate of $0.2 \mathrm{~g} / \mathrm{L}$ of milk) and salt (at a rate of $20 \mathrm{~g} / \mathrm{L}$ of milk) were placed inside a cloth with closed ends, and submerged in the milk through the opening of the cover.

Following coagulation - which took ca. $45 \mathrm{~min}$, the curd was cut into relative small particles using the vertical knives, rotated at a speed of $2 \mathrm{rpm}$ for $3 \mathrm{~min}$. The whey-containing curd was left to set for $2 \mathrm{~min}$, and then the periscope was manually pulled up to approximately coincide with the free whey surface - and opened so as to permit removal of whey. The periscope was afterwards gradually stepped down, so that the aperture would stand at the free surface of whey at all times.

When this operation had been completed, the aperture of the periscope was closed, and it was returned to its initial rest position. The curd was then stirred using the knives for an extra $5 \mathrm{~min}$, prior to vat discharge. The discharge outlet - located on the bottom wall of the vat, was manually opened, and the curd was allowed to flow into the cylinder. The curd (together with residual whey) fell down by gravity, from the vat into the vertical elongated tube. Care was exercised so that the cutting frame of the perforated cylinder was open, and that its lower aperture was closed. When said perforated cylinder had been completely filled, the vat outlet was closed, and the cutting plate was pushed horizontally by hand - so as to cut halfway through the elongated cylindrical cheese curd, at a predetermined location. Note that, at this moment, the cheese mould was still attached to the lower end of the perforated cylinder, exactly above the blocking plate - so that, after removing the latter, the cheese (with a height given by the distance between the blocking plate and the cutting plate) fell down into the mould. As the first cheese was separated from the cylinder, another cheese could be manufactured by iterating stepwise this procedure - until all curd had been delivered out from the vat.

Drainage of whey was completed via pressing the fresh cheese, in its mould, with the aid of a standard pneumatic press. Afterwards, the cheese was taken out and duly weighed - so as to allow calculation of cheese yield. Finally, cheese was subject to ripening under controlled temperature and relative humidity.

At the end of the cheesemaking cycle, the CIP was operated within the apparatus. 


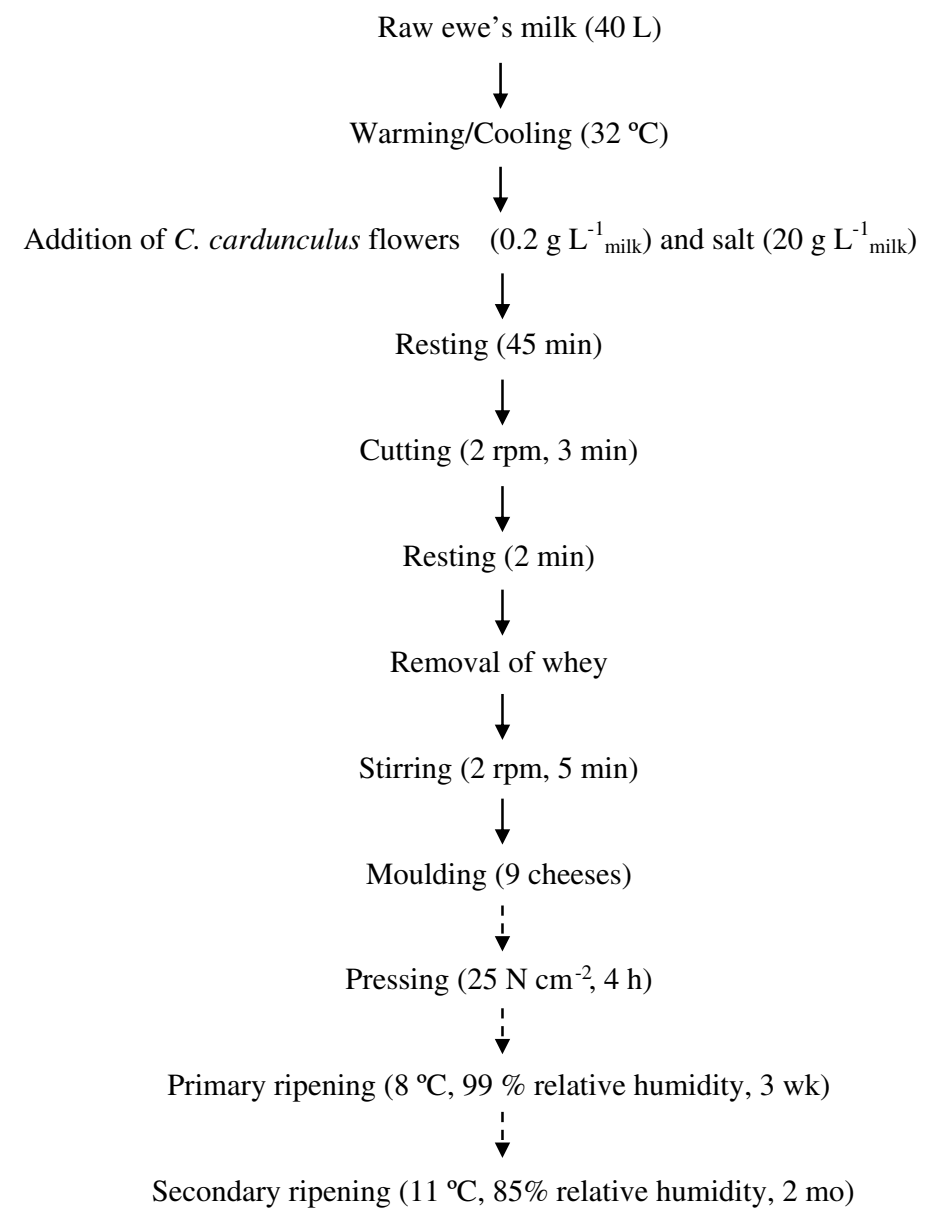

Fig. 3. Flow diagram of cheese manufacturing procedure using the novel cheesemaking apparatus (solid arrows).

\section{Cheese yield}

Actual cheese yields were duly calculated, and expressed as $\mathrm{kg}$ per $100 \mathrm{~kg}$ of ewe's milk used - following also the procedure suggested by Kosikowski and Mistry (1997) of moisture-adjusted cheese yield, calculated by mathematically correcting the actual yield using the mean moisture content of the cheese. Lumped component (i.e. protein or fat) recovery was calculated as the weight of said component in the final cheese, divided by its original weight in the cheesemaking milk - expressed as kg per $100 \mathrm{~kg}$.

\section{Statistical analysis}

Experiments were replicated three times, following a randomised block design. Cheese yield and component recovery data were analyzed using one-way Analysis of Variance (ANOVA), via the SPSS package v. 13.0 (Chicago IL, USA). Differences between treatment means were considered significant at the level of $P<0.05$.

\section{Results and discussion}

The perforated cylinder allowed the whey separation and the curd moulding steps to be combined to advantage in a single procedure - without touching the curd with the (bare) hand. The resulting cheeses were also much more uniform to the eye. Significant differences $(P<0.05)$ in cheese yield were found, between cheeses manufactured artisanally or using the novel apparatus (Table 1).

Several factors - such as milk composition and cheesemaking techniques, contribute to variations in actual cheese yield: e.g. losses of curd in disposed whey affect cheese yield markedly. Since the components that mainly determine cheese yield are casein and fat contents of the cheesemaking milk (Bullens, Krawczyk, \& Geithman, 1994), fat and protein recovery were also computed so as to help in elucidating the meaning of the yields obtained. Use of the novel apparatus produced a significant increase in fat recovery, as compared to artisanal cheesemaking. Conversely, ANOVA showed that the cheesemaking protocol did not contribute significantly to differences in protein recovery. Such a higher fat recovery may be related to our mechanical process - in which manual handling of curd prior to mechanical pressing does not exist any more, which probably disturbs less the fat globule pattern.

The time spent in manufacturing Serra da Estrela cheese via the novel apparatus is notoriously lower than that following the artisanal process - especially from the moment of cutting on: using the latter, a cheesemaker takes ca. $3 \mathrm{~h}$ to manufacture nine cheeses (from an initial batch of $40 \mathrm{~L}$ of milk), whereas that time requirement drops to only $1 \mathrm{~h}$ 
Table 1

Average values ( \pm standard deviation) of duplicates of three batches of each type of ewe's raw milk cheeses, pertaining to actual and moisture-adjusted yields, as well as bulk nutrient - protein and fat, recoveries, produced by artisanal and semi-automated procedures

\begin{tabular}{llr}
\hline Parameter & Cheesemaking procedure & \\
\cline { 2 - 3 } & Artisanal & Semi-automated \\
\hline Actual yield $\left(\mathrm{kg}_{\text {cheese }} 100 \mathrm{~kg}_{\text {milk }}^{-1}\right)$ & $25.55 \pm 0.90^{\mathrm{a}}$ & $29.20 \pm 1.39^{\mathrm{b}}$ \\
Moisture-adjusted yield $\left(\mathrm{kg}_{\text {cheese }} 100 \mathrm{~kg}_{\text {milk }}^{-1}\right)$ & $27.23 \pm 0.29^{\mathrm{a}}$ & $34.90 \pm 0.68^{\mathrm{b}}$ \\
Protein recovery $\%, \mathrm{w} / \mathrm{w})$ & $1.85 \pm 0.13^{\mathrm{a}}$ & $1.89 \pm 0.25^{\mathrm{a}}$ \\
Fat recovery $(\%, \mathrm{w} / \mathrm{w})$ & $0.67 \pm 0.07^{\mathrm{a}}$ & $0.81 \pm 0.05^{\mathrm{b}}$ \\
\hline
\end{tabular}

a,b Within a row, means not followed by the same superscript are significantly different $(P<0.05)$.

with the novel apparatus, for the same initial batch of milk and final batch of cheeses. Moreover, the CIP system reduces substantially the time taken by the labour-intensive cleaning of equipment that is required afterwards, prior to equipment shutdown.

The combined effects of a higher fat recovery, a less time- and labour-intensive process, and more standardised final cheeses thus fully justify investment on the proposed novel apparatus.

\section{Acknowledgements}

This work has been partially funded by ICPME - project PROTOTIPO: PROdução, por Tecnologias Optimizadas, de lacTIcinios POrtugueses (administered by Agência de Inovação, Portugal) and by AGRO - project 778 ECOSEGURANÇA: promoção da ECO-Eficiência e SEGurança em sistemas de prodUção tRadicionAis e iNovadores à escala da exploraÇão Agrícola (administered by Instituto Nacional de Investigação Agrária e das Pescas). Financial support for author P.J.M. Reis was provided by PRAXIS XXI, via a PhD fellowship ref. BD/ 19752/99 (administered by Fundação para a Ciência e a Tecnologia, Portugal). ANCOSE is gratefully acknowledged for technical assistance in implementation of the cheesemaking protocol, and ARSOPI (Vale de Cambra, Portugal) for technical assistance in design and building of the novel apparatus.

\section{References}

Bullens, C., Krawczyk, G., \& Geithman, L. (1994). Reduced-fat cheese products using carrageenan and microcrystalline cellulose. Food Technology, 48(1), 79-81.

Dias, P. M. D. (1992). Ensaios de Vários Tipos de Salga em Queijos de Castelo Branco. Castelo Branco, Portugal: Escola Superior Agrária do Instituto Politécnico de Castelo Branco.

Freitas, A. C., Macedo, A. C., \& Malcata, F. X. (2000). Review: technological and organoleptic issues pertaining to cheeses with denomination of origin manufactured in the Iberian Peninsula from ovine and caprine milks. Food Science and Technology International, 6, 351-370.

IDRHa-MADRP (2005). Produtos Tradicionais com Nomes Protegidos. Apresentação de Dados sobre a Produção, Preços e Comercialização em 2003. Lisboa, Portugal: Instituto de Desenvolvimento Rural e Hidráulica, Ministério da Agricultura do Desenvolvimento Rural e das Pescas.

Kosikowski, F. V., \& Mistry, V. V. (1997). Analysis. In F. V. Kosikowski \& V. V. Mistry (Eds.), Cheese and Fermented Milk Foods. Westport CT, USA: Kosikowski \& Associates.

Macedo, A. C., \& Malcata, F. X. (1997). Technological optimization of the manufacture of Serra cheese. Journal of Food Engineering, 31, 433-447.

Macedo, A. C., Malcata, F. X., \& Oliveira, J. C. (1993). The technology, chemistry, and microbiology of Serra cheese: a review. Journal of Dairy Science, 76, 1725-1739.

Macedo, A. C., Malcata, F. X., \& Oliveira, J. C. (1997). Effect of production factors and ripening conditions on the characteristics of Serra cheese. International Journal of Food Science and Technology, 32, 501-511.

Macedo, A. C., Tavares, T. G., \& Malcata, F. X. (2004). Influence of native lactic acid bacteria on the microbiological, biochemical and sensory profiles of Serra da Estrela cheese. Food Microbiology, 21, 233-240.

NP-1922 (1985). Serra da Estrela. Definição, características e marcação. Direcção-Geral da Qualidade. Diário da República série III, No. 30.

Roseiro, L. B., Wilbey, R. A., \& Barbosa, M. (2003). Serpa cheese: technological, biochemical and microbiological characterisation of a PDO ewe's milk cheese coagulated with Cynara cardunculus L. Le Lait, 83, 469-481.

Sousa, M. J., \& Malcata, F. X. (1997a). Comparative biochemical evolution during ripening of bovine, ovine and caprine cheeses manufactured with extracts of flowers of Cynara cardunculus. Zeitschrift fur Lebensmittel-Untersuchung und-Forschung A, 205, 97-103.

Sousa, M. J., \& Malcata, F. X. (1997b). Ripening of ovine milk cheeses: effects of plant rennet, pasteurization, and addition of starter on lipolysis. Food Chemistry, 59, 427-432.

Tavaria, F. K., \& Malcata, F. X. (1998). Microbiological characterization of Serra da Estrela cheese throughout its Appellation d'Origine Protégée region. Journal of Food Protection, 61, 601-607.

Vasconcelos, M.M.F.P. (1990). Estudo do Queijo Azeitão - Melhoramento da Tecnologia Tradicional e sua Influência nas Características do Queijo. Ph.D., Instituto Nacional de Investigação Agrária, Lisboa, Portugal. 